\title{
Composition and structure design of three-layered composite phosphors for high color rendering chip-on-board light-emitting diode devices
}

\author{
Xin LIU $^{a, b, \dagger}$, Xinglu QIAN ${ }^{c, \uparrow}$, Peng ZHENG ${ }^{d}$, Xiaopu CHEN $^{a, b}$, Yagang FENG ${ }^{a, b}$, \\ Yun $\mathrm{SHI}^{a, b}$, Jun $\mathrm{ZOU}^{c, e, *}$, Rongjun $\mathrm{XIE}^{d, *}$, Jiang $\mathrm{LI}^{a, b, *}$ \\ ${ }^{a}$ Key Laboratory of Transparent Opto-functional Inorganic Materials, Shanghai Institute of Ceramics, \\ Chinese Academy of Sciences, Shanghai 201899, China \\ ${ }^{b}$ Center of Materials Science and Optoelectronics Engineering, University of Chinese Academy of Sciences, \\ Beijing 100049, China \\ ${ }^{c}$ School of Science, Shanghai Institute of Technology, Shanghai 201418, China \\ ${ }^{d}$ College of Materials, Xiamen University, Xiamen 361005, China \\ ${ }^{e}$ Institute of New Materials \& Industrial Technology, Wenzhou University, Wenzhou 325024, China
}

Received: December 24, 2020; Revised: January 30, 2021; Accepted: February 23, 2021

(C) The Author(s) 2021.

\begin{abstract}
A three-layered phosphor structure was designed and prepared by the spin coating of $\mathrm{BaSi}_{2} \mathrm{~N}_{2} \mathrm{O}_{2}: \mathrm{Eu}$ (cyan-emitting) and ( $\left.\mathrm{Sr}, \mathrm{Ca}\right) \mathrm{AlSiN}_{3}: \mathrm{Eu}$ (red-emitting) phosphor films on the yellowemitting $\mathrm{Y}_{3} \mathrm{Al}_{5} \mathrm{O}_{12}$ : $\mathrm{Ce}$ (YAG:Ce) phosphor ceramic synthesized by the solid-state reaction under vacuum sintering. In order to achieve high color rendering lighting, the influence of the composition and structure of the three-layered phosphors on the optical, thermal, and electrical properties of the chip-on-board (COB) packaged white-light-emitting diodes (WLEDs) was studied systematically. The WLED with the structure of "red+cyan+yellow" $(\mathrm{R}+\mathrm{C}+\mathrm{Y})$ three-layered phosphor generated neutral white light and had a luminous efficacy of $75 \mathrm{~lm} / \mathrm{W}$, the fidelity index $\left(R_{\mathrm{f}}\right)$ of 93 , the gamut index $\left(R_{\mathrm{g}}\right)$ of 97 , and the correlated color temperature (CCT) of $3852 \mathrm{~K}$. Under the excitation of laser diode (LD), the layer-structured phosphor yielded the white light with a luminous efficacy of $120 \mathrm{~lm} / \mathrm{W}$, color rendering index (CRI) of 90, and CCT of $5988 \mathrm{~K}$. The result indicates that the three-layered phosphor structure is a promising candidate to achieve high color rendering and high luminous efficacy lighting.
\end{abstract}

Keywords: three-layered composite phosphor; structure design; high color rendering; luminous efficacy

\section{Introduction}

Solid-state lighting devices based on white-light-emitting

\footnotetext{
$\dagger$ Xin Liu and Xinglu Qian contributed equally to this work.

* Corresponding authors.

E-mail: J. Li, lijiang@mail.sic.ac.cn;

J. Zou, zoujun@sit.edu.cn;

R.Xie, rjxie@xmu.edu.cn
}

diodes (WLEDs) have replaced traditional incandescent and fluorescent lamps in the market due to their advantages of long lifespan, environmental friendliness, high reliability, and high efficiency [1]. To meet the requirements of some special applications, such as automobile headlamp, ocean lighting, and long-distance street lighting, the state-of-the-art white-light illumination systems are developing towards high power and high brightness. Recently, laser diodes (LDs) have become 
attractive excitation sources to achieve high brightness and high-quality white light if combined with phosphors, because the external quantum efficiency of LDs increases linearly as a function of operating current without the problem of "efficiency droop" $[2,3]$.

A typical approach to obtain high-power white light is to combine high-brightness blue light-emitting diodes (LEDs) or LDs with appropriate yellow phosphor converters [4-6]. The thermally robust phosphor ceramics are believed to be the best choice of phosphor converters, compared to their counterparts including phosphor powders, phosphor in glass, and single crystals $[7,8]$. The phosphor ceramics possess superior advantages, such as (i) strong mechanical properties, (ii) easy control of light scattering via component and porosity regulation, and (iii) much less degradation in luminous efficacy and color shift [5,9,10]. Also, the great microstructures (such as grain sizes, grain boundaries, pores, secondary phase, and surface structure) and optical property (emission wavelength, transmittance, etc.) tunability let phosphor ceramics get more freedom of performance design [11-14]. The highly efficient $\mathrm{Y}_{3} \mathrm{Al}_{5} \mathrm{O}_{12}: \mathrm{Ce}$ (YAG:Ce) ceramic phosphors have been investigated extensively, and they often manifest high efficiency but suffer from low color rendering index (CRI) value, which indicates that the white light produced by using YAG:Ce is not accepted for general lighting. An effective method to obtain high CRI is to co-doping ions $\left(\mathrm{Pr}^{3+}, \mathrm{Cr}^{3+}, \mathrm{Mn}^{2+}\right.$, etc.) or partial substitute of $\mathrm{Y}^{3+}$ by different ions $\left(\mathrm{Gd}^{3+}\right.$, etc.) in YAG:Ce to add red spectral components in its spectrum, but usually with a sacrifice in luminous efficacy [15-19]. Alternatively, composite phosphor ceramics consisting of both red- and yellow-emitting phosphors are expected to realize high color rendering lighting. Pricha et al. [20] prepared $\mathrm{CaAlSiN}_{3}: \mathrm{Eu}$ and YAG:Ce double-layered composite ceramics. However, the composite ceramics had severe interfacial chemical interactions because of the composition difference between these two phosphors. To overcome this interfacial reaction problem, it would be a good way to coat a red phosphor film on the YAG:Ce ceramic. Many red phosphors with excellent performance have been studied recently $[21,22]$. Among these red phosphors, $(\mathrm{Sr}, \mathrm{Ca}) \mathrm{AlSiN}_{3}: \mathrm{Eu}$ is considered as the ideal red-emitting phosphor for high-power LEDs (hp-LEDs) or LDs because it has wide excitation and emission bands, as well as high thermal quenching temperatures [23-25].

Nowadays, a new concept named "full-spectrum lighting" (FSL), which mimics the spectrum of natural sunlight, has attracted more and more attention [26]. Full spectrum is defined as the spectral wavelength covering all visible regions with a small amount of ultraviolet and infrared light, and the spectrum should be continuous without extremely disproportionate peaks and troughs. However, except for the red composition often reported by researchers, the cyan gap in the 480-520 nm region also restricts the development of FSL in YAG:Ce phosphor ceramic [27-32]. Hence, a cyan phosphor is important to achieve FSL [33]. $\mathrm{BaSi}_{2} \mathrm{~N}_{2} \mathrm{O}_{2}: \mathrm{Eu}$, which possesses an emission band centered at $\sim 495 \mathrm{~nm}$ (full width at half maxima $(\mathrm{FWHM}) \approx 32 \mathrm{~nm}$ ), is an excellent cyan phosphor due to its high quantum efficiency [34].

In this work, to realize high color rendering, the red-emitting $(\mathrm{Sr}, \mathrm{Ca}) \mathrm{AlSiN}_{3}$ : $\mathrm{Eu}$ and the cyan-emitting $\mathrm{BaSi}_{2} \mathrm{~N}_{2} \mathrm{O}_{2}$ :Eu phosphors were chosen, and their films were coated on the YAG:Ce phosphor ceramic. The influence of the concentration of phosphor films and the phosphor ceramics of the three-layered phosphor on optical, thermal, and electrical properties of the packaged WLEDs was systematically investigated. Also, the effect of different stacking structures on the composite phosphor was studied at a specific concentration of the three phosphors. Furthermore, the optimal three-layered composite phosphor was combined with a blue LD to evaluate its suitability in laser-driven lighting. IES TM-30-15 evaluation system, in which the fidelity index $\left(R_{\mathrm{f}}\right)$ and the gamut index $\left(R_{\mathrm{g}}\right)$ are used to evaluate the color rendering of the light simultaneously, was used in the evaluation of the white LED devices.

\section{Experimental}

\section{1 Fabrication of three-layered phosphors}

The transparent YAG:Ce phosphor ceramic was fabricated by the solid-state reaction and vacuum sintering method. High purity powders of $\mathrm{Y}_{2} \mathrm{O}_{3}$ (99.999\%, Fujian Changting Golden Dragon Co., Ltd., China), $\alpha-\mathrm{Al}_{2} \mathrm{O}_{3}(99.99 \%$, Taimei Chemicals Co., Ltd., China), and $\mathrm{CeO}_{2}$ (99.995\%, Fujian Changting Golden Dragon Co., Ltd., China) were weighted according to the chemical formula $\left(\mathrm{Ce}_{x} \mathrm{Y}_{1-x}\right)_{3} \mathrm{Al}_{5} \mathrm{O}_{12} \quad(x=0.0005$, $0.001,0.0015)$, and no sintering aids were added. After ball-milled in ethanol for $12 \mathrm{~h}$ at a rotation speed of $279 \mathrm{r} / \mathrm{min}$, the slurry was dried at $70{ }^{\circ} \mathrm{C}$ in the oven. 
The obtained powder was sieved through a 200 -mesh screen, calcined at $600{ }^{\circ} \mathrm{C}$ in air for $4 \mathrm{~h}$, dry pressed into green bodies $(\Phi=20 \mathrm{~mm})$, and then cold isostatically pressed under a pressure of $250 \mathrm{MPa}$. The green bodies were sintered at $1780{ }^{\circ} \mathrm{C}$ in the vacuum of $5.0 \times 10^{-5} \mathrm{~Pa}$ for $10 \mathrm{~h}$ and air-annealed in the oven at $1450{ }^{\circ} \mathrm{C}$ for $10 \mathrm{~h}$. The phosphor ceramic was polished to the different thicknesses by a polyurethane polishing machine with diamond micronized powder as polishing slurry for further measurements and preparation of three-layered phosphors.

The cyan and red phosphor films were prepared by the spin coating method. $\mathrm{BaSi}_{2} \mathrm{~N}_{2} \mathrm{O}_{2}$ :Eu phosphor, $(\mathrm{Sr}, \mathrm{Ca}) \mathrm{AlSiN}_{3}$ :Eu phosphor (Yantai Bright Photoelectric Material Co., Ltd., China), glue A (mixture of epoxy resin and benzyl alcohol, 5351A, Shanghai Huitian New Material Co., Ltd., China), and glue B (mixture of triethylenetriamine and water, $5351 \mathrm{~B}$, Shanghai Huitian New Material Co., Ltd., China) are commercially available. Curing reaction can occur after mixing glues $\mathrm{A}$ and $\mathrm{B}$, which can facilitate films curing and molding. The cyan film has the mass ratio of glue A:glue B: $\left(\mathrm{BaSi}_{2} \mathrm{~N}_{2} \mathrm{O}_{2}: \mathrm{Eu}\right)$ of 1:1:0.05, 1:1:0.07, and 1:1:0.09, and the red film has the mass ratio of glue A:glue $\mathrm{B}:\left((\mathrm{Sr}, \mathrm{Ca}) \mathrm{AlSiN}_{3}: \mathrm{Eu}\right)$ of $1: 1: 0.01, \quad 1: 1: 0.02$, and 1:1:0.03. The $\mathrm{BaSi}_{2} \mathrm{~N}_{2} \mathrm{O}_{2}: \mathrm{Eu}$, glue $\mathrm{A}$, and glue $\mathrm{B}$ were mixed with a glass rod in a mixing pot. After defoaming in a vacuum defoamer, the mixture was evenly dripped on the rotating glass substrate, and the thickness of the final film can be changed by adjusting the rotation time and speed. The glass substrate coated with the mixture was put in the oven at $80{ }^{\circ} \mathrm{C}$ for $20 \mathrm{~min}$ and at $150{ }^{\circ} \mathrm{C}$ for another $20 \mathrm{~min}$ to reach a compact film. Then the phosphor film was scraped off with a scraper from bottom to top of the substrate without any damage for further tests and preparation of three-layered phosphors. The $(\mathrm{Sr}, \mathrm{Ca}) \mathrm{AlSiN}_{3}: \mathrm{Eu}$ red phosphor films were prepared in the same way. The $\mathrm{BaSi}_{2} \mathrm{~N}_{2} \mathrm{O}_{2}: \mathrm{Eu}$ film, $(\mathrm{Sr}, \mathrm{Ca}) \mathrm{AlSiN}_{3}: \mathrm{Eu}$ film, and YAG:Ce ceramic were stacked in different orders to prepare different threelayered phosphor structures. Similar to the previous film preparation, the different composite phosphors were prepared by spin-coating a mixture of phosphor and glues onto a ceramic or another phosphor film on the ceramic rather than a glass substrate.

\section{2 Characterization}

The surface morphologies of the phosphor ceramic and phosphor films were characterized by a field emission scanning electron microscope (FESEM, SU-8220, Hitachi, Japan), equipped with an energy dispersive $\mathrm{X}$-ray spectroscope (EDS). The total transmittances of the ceramic and films over the wavelength ranging from 250 to $800 \mathrm{~nm}$ were recorded by an ultravioletvisible-near infrared (UV-Vis-NIR) spectrophotometer (Cary 5000, Varian Medical System Inc., USA). The room-temperature photoluminescence (PL) and photoluminescence excitation (PLE) spectra were measured by the fluorescence spectrophotometer (FS5, Edinburgh Instruments, USA). Another fluorescence spectrophotometer (F-4600, Hitachi, Japan) equipped with a xenon lamp as the excitation source was used to measure the temperature-dependent PL and PLE spectra in the temperature range from 25 to $225{ }^{\circ} \mathrm{C}$. In order to optimize the luminous performance of LEDs, YAG:Ce ceramic (Y), cyan phosphor film (C), and red phosphor film (R) were combined in six different three-layer structures (e.g., the " $\mathrm{C}+\mathrm{R}+\mathrm{Y}$ " means that $\mathrm{C}$ is attached directly to LEDs and $\mathrm{Y}$ is far away from the LEDs). These phosphors were then combined with chip-on-board (COB) LED devices to fabricate WLEDs. The electroluminescent properties, such as the electroluminescence (EL) spectrum, luminous flux, luminous efficacy, $R_{\mathrm{f}}, R_{\mathrm{g}}$, and correlated color temperature (CCT) of the WLEDs, were tested using a spectroradiometer with an integrating sphere (HASS2000, Hangzhou, China). The optical properties of the composite phosphor with the $\mathrm{C}+\mathrm{R}+\mathrm{Y}$ structure under the laser excitation were measured by a spherespectroradiometer which is equipped with an integrating sphere (Labsphere Inc., USA), a charge-coupled device (CCD) spectrometer (HR4000, Ocean Optics, USA), and a high-power blue laser light source with adjustable output power.

\section{Results and discussion}

Figure 1(a) shows the surface morphology of the YAG:Ce sample. It can be seen that YAG:Ce ceramic has regular grains with an average grain size of $\sim 5 \mu \mathrm{m}$. A number of closed pores are present in the sample. Although these pores as light scattering centers will decrease the transmittance of the sample, they are beneficial to improving the conversion efficiency of phosphor ceramics by increasing the interaction between incident blue light and the ceramic, which results in more blue light being absorbed [35]. The fractured 

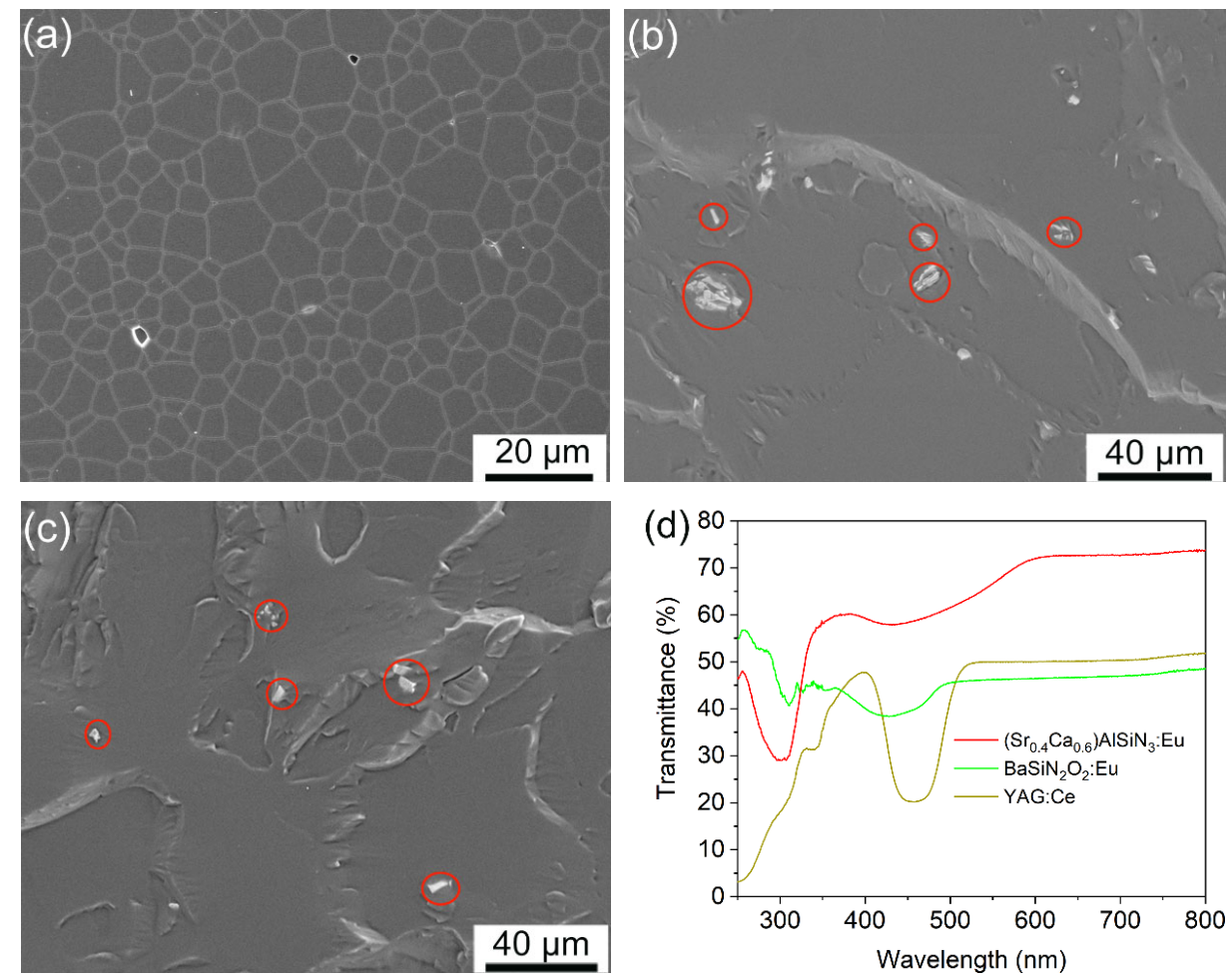

Fig. 1 FESEM mrophologies of (a) YAG:Ce ceramic, (b) $\mathrm{BaSi}_{2} \mathrm{~N}_{2} \mathrm{O}_{2}: \mathrm{Eu}$ film, and (c) ( $\left.\mathrm{Sr}, \mathrm{Ca}\right) \mathrm{AlSiN}_{3}: \mathrm{Eu}$ film. (d) The total transmittance of phosphor mentioned above.

surfaces of the $\mathrm{BaSi}_{2} \mathrm{~N}_{2} \mathrm{O}_{2}$ :Eu and $(\mathrm{Sr}, \mathrm{Ca}) \mathrm{AlSiN}_{3}: \mathrm{Eu}$ phosphor films are shown in Figs. 1(b) and 1(c). The micron-sized phosphor particles, which have been circled in the graphs, are loosely dispersed in the polymer matrix. As seen in Fig. 1(d), both the ceramic and phosphor films have good optical transmittance (the thicknesses of YAG:Ce ceramic, $(\mathrm{Sr}, \mathrm{Ca}) \mathrm{AlSiN}_{3}: \mathrm{Eu}$ red film, and $\mathrm{BaSi}_{2} \mathrm{~N}_{2} \mathrm{O}_{2}$ :Eu cyan film are 1, 0.4, and $0.4 \mathrm{~mm}$, respectively), which is beneficial to the entry of the blue excitation light and the extraction of the emitted light.

Figure 2 shows the PLE and PL spectra of YAG:Ce ceramics, $\mathrm{BaSi}_{2} \mathrm{~N}_{2} \mathrm{O}_{2}: \mathrm{Eu}$ films, and ( $\left.\mathrm{Sr}, \mathrm{Ca}\right) \mathrm{AlSiN}_{3}: \mathrm{Eu}$ films with different concentrations. The illustrations are photographs of the corresponding phosphor ceramic or films. As seen from Fig. 2(a), two absorption bands at 340 and $460 \mathrm{~nm}$ can be found, which can be attributed to $4 \mathrm{f} \rightarrow 5 \mathrm{~d}_{2}$ and $4 \mathrm{f} \rightarrow 5 \mathrm{~d}_{1}$ transitions of $\mathrm{Ce}^{3+}$, respectively. A broad emission band, assigned to the transition of the $5 \mathrm{~d}$ excited state to ${ }^{2} \mathrm{~F}_{5 / 2}$ and ${ }^{2} \mathrm{~F}_{7 / 2}$ ground states, can be found $[6,15,36]$. It can be seen that the emission intensity of the YAG:Ce ceramic increases with the increase of the $\mathrm{Ce}^{3+}$ concentration. As shown in Fig. 2(b), $\mathrm{BaSi}_{2} \mathrm{~N}_{2} \mathrm{O}_{2}$ :Eu phosphor films yield a broad excitation ranging from 250 to $475 \mathrm{~nm}$, corresponding to the $4 \mathrm{f}^{7}\left(8 \mathrm{~S}_{7 / 2}\right) \rightarrow 4 \mathrm{f}^{6} 5 \mathrm{~d}^{1}$ transition of $\mathrm{Eu}$, and a narrow emission band with the peak position at $492 \mathrm{~nm}$. The PL intensity increases with increasing concentration of phosphor in the film [33]. When the $\mathrm{Eu}$ ions are doped in $(\mathrm{Sr}, \mathrm{Ca}) \mathrm{AlSiN}_{3}$, the emission peak which can be attributed to the transition of $4 \mathrm{f}^{6} 5 \mathrm{~d}^{1} \rightarrow$ $4 \mathrm{f}^{7}$ is located at $634 \mathrm{~nm}$ [37-40]. The PL intensity is obviously enhanced with the increase of the phosphor concentration. The PL/PLE spectra of the YAG:Ce ceramic, $\mathrm{BaSi}_{2} \mathrm{~N}_{2} \mathrm{O}_{2}: \mathrm{Eu}$, and $(\mathrm{Sr}, \mathrm{Ca}) \mathrm{AlSiN}_{3}:$ Eu phosphor films under the excitation of $460 \mathrm{~nm}$ are compared in Fig. 2(d). The cyan and yellow emissions can be reabsorbed by the red phosphor due to the large spectral overlap between the excitation spectrum of $(\mathrm{Sr}, \mathrm{Ca}) \mathrm{AlSiN}_{3}: \mathrm{Eu}$ and the emission spectra of $\mathrm{BaSi}_{2} \mathrm{~N}_{2} \mathrm{O}_{2}$ :Eu and YAG:Ce. Also, YAG:Ce can convert the emission of the cyan phosphor to yellow light. Therefore, it is necessary to optimize the structure of the three-layered phosphors to reach the optimal optical properties (high luminous efficacy and color rendering). $\mathrm{Ce}^{3+}$ almost displays a single exponential fluorescent decay model with a typical lifetime of about 65 ns (Fig. 2(e)). As shown in Figs. 2(f) and 2(g), when $\mathrm{Eu}^{2+}$ is doped in $\mathrm{BaSi}_{2} \mathrm{~N}_{2} \mathrm{O}_{2}$ and $(\mathrm{Sr}, \mathrm{Ca}) \mathrm{AlSiN}_{3}$, their fluorescence lifetime $(\tau)$ are 12.7 and $8.7 \mu$ s, respectively. 

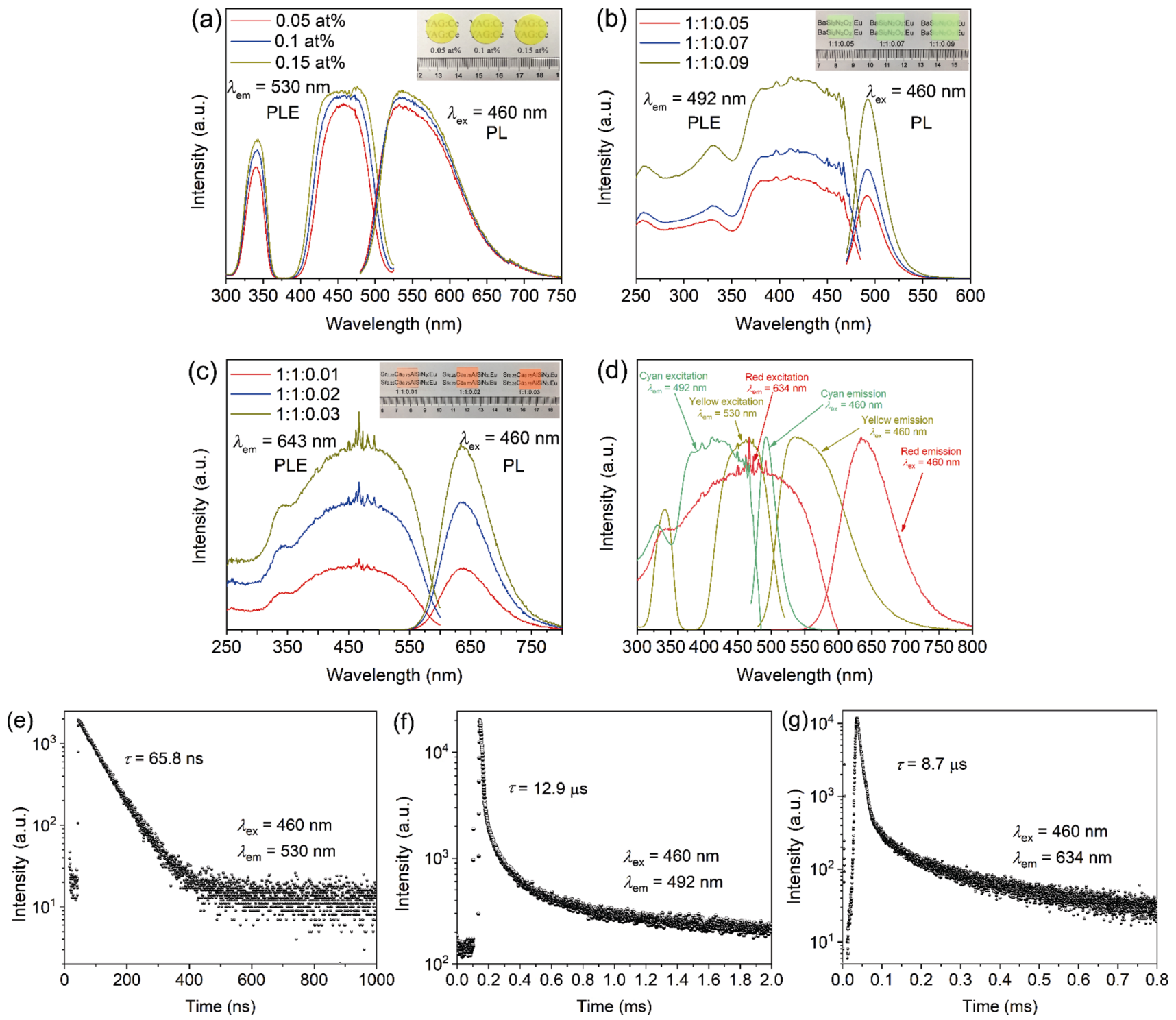

Fig. 2 PLE and PL spectra of (a) YAG:Ce ceramics, (b) $\mathrm{BaSi}_{2} \mathrm{~N}_{2} \mathrm{O}_{2}$ :Eu films, and (c) (Sr,Ca)AlSiN $\mathrm{N}_{3}:$ Eu films with different concentrations. (d) Normalized PL spectra of the above three phosphors under the $460 \mathrm{~nm}$ blue light excitation. Fluorescent decay curves for (e) YAG:Ce ceramic, (f) $\mathrm{BaSi}_{2} \mathrm{~N}_{2} \mathrm{O}_{2}$ : Eu film, and (g) $(\mathrm{Sr}, \mathrm{Ca}) \mathrm{AlSiN}_{3}: \mathrm{Eu}$ film.

One of the key parameters to evaluate phosphor used for WLEDs is the thermal stability $l_{x} \cdot l_{\mathrm{RT}}$. Figure 3 shows the temperature-dependent PL spectra of YAG:Ce ceramic, $\mathrm{BaSi}_{2} \mathrm{~N}_{2} \mathrm{O}_{2}: \mathrm{Eu}$ film, and $(\mathrm{Sr}, \mathrm{Ca}) \mathrm{AlSiN}_{3}: \mathrm{Eu}$ film under $460 \mathrm{~nm}$ excitation. The thermal stability is defined as the ratio of the PL intensity at high temperatures to that at the room temperature (Fig. 3(d)). The YAG:Ce ceramic shows the excellent thermal stability. With the increase of the temperature, the PL intensity decreases slightly, and it can maintain $92.5 \%$ at $225{ }^{\circ} \mathrm{C}$. The red shift of the emission peak is also observed, which is mainly caused by reabsorption of the high-energy part of the emission [41]. It indicates the phosphor ceramic can maintain the luminous efficacy and color stability when used as the color converter. It is worthwhile to mention that the emission intensity of $\mathrm{BaSi}_{2} \mathrm{~N}_{2} \mathrm{O}_{2}: \mathrm{Eu}$ or $(\mathrm{Sr}, \mathrm{Ca}) \mathrm{AlSiN}_{3}:$ Eu phosphor film decreases with the increase of the temperature due to the thermal quenching, which is caused by excited state electrons going back to the ground state in a non-radiative process [42]. The insets in Figs. 3(b) and 3(c) are the temperature-dependent PL spectra of these two phosphors without the mixtures of A and B glues, and they exhibit the same trend as the spectra of the corresponding phosphor films. The PL intensity of $\mathrm{BaSi}_{2} \mathrm{~N}_{2} \mathrm{O}_{2}$ :Eu drops to $57.8 \%$ when the temperature rises to $225{ }^{\circ} \mathrm{C}$, and the PL intensity of $(\mathrm{Sr}, \mathrm{Ca}) \mathrm{AlSiN}_{3}: \mathrm{Eu}$ phosphor film can maintain $66.7 \%$ of its initial value. 

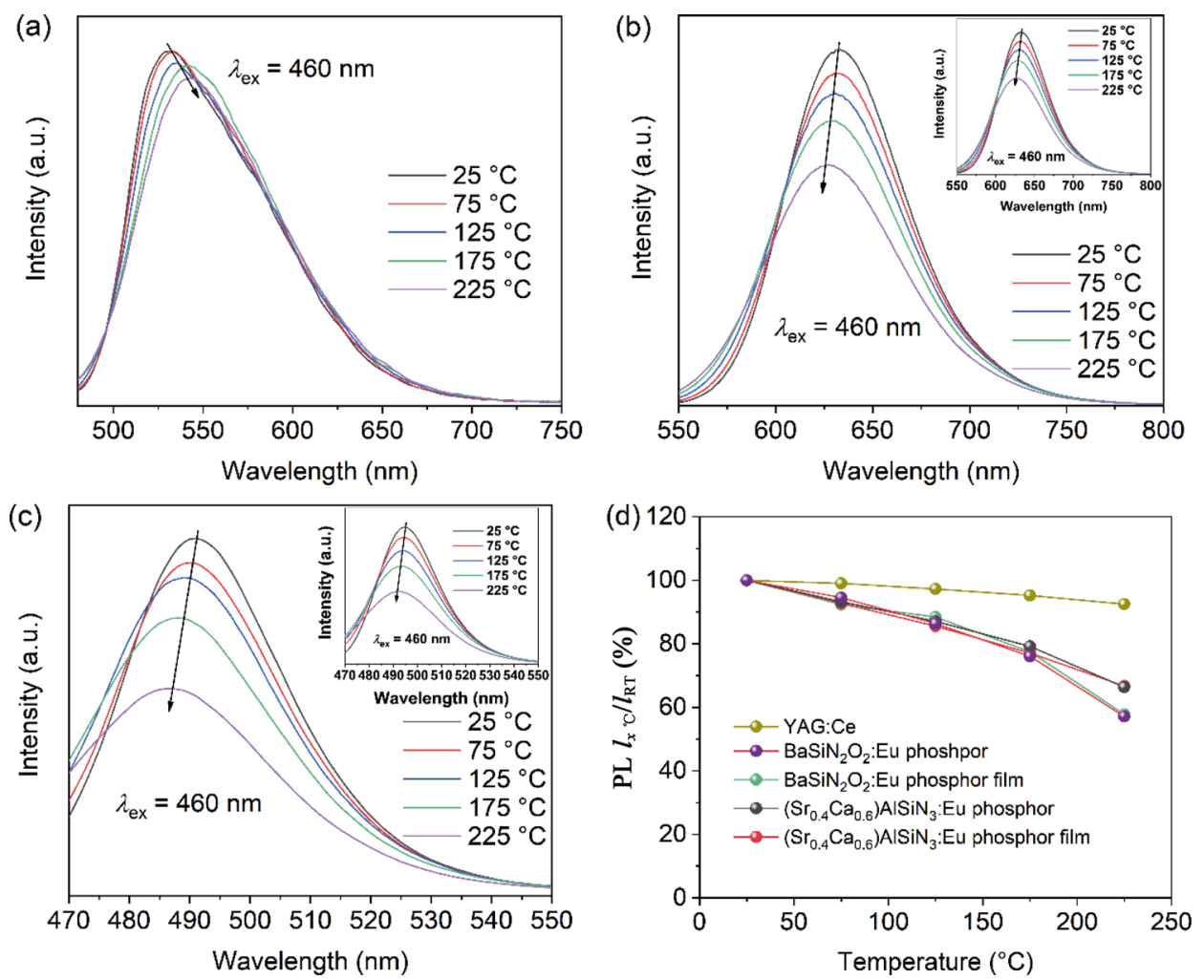

Fig. 3 Temperature-dependent PL spectra of (a) YAG:Ce ceramic, (b) ( $\mathrm{Sr}, \mathrm{Ca}) \mathrm{AlSiN}_{3}$ :Eu film, and (c) $\mathrm{BaSi}_{2} \mathrm{~N}_{2} \mathrm{O}_{2}: \mathrm{Eu}_{\text {film. }}$ (d) Thermal stability of the five types of phosphors with the increasing temperature from 25 to $225{ }^{\circ} \mathrm{C}$. The insets in (b) and (c) are the corresponding PL spectra of the phosphor without the mixtures of A and B glues.

Also, the emission peak blue shifts slightly as the temperature increases due to the thermally activated phonon-assisted tunneling, which can be described in terms of the thermal back-transfer from the lower energy excited states to the higher energy excited states with the assistance of thermal active phonons [43].

In order to screen the optimal spectral composition, the cyan and red films with different phosphor concentrations were combined with YAG:Ce ceramics with different $\mathrm{Ce}^{3+}$ concentrations to investigate their optical properties under the excitation of the $\mathrm{COB}$ packaged $460 \mathrm{~nm}$ blue light (Table 1). Similar to the previous film preparation, the different composite phosphors were prepared by spin-coating a mixture of phosphor and glues onto a ceramic or another phosphor film on the ceramics rather than a glass substrate. The $\mathrm{R}+\mathrm{C}+\mathrm{Y}$ structure was used for measurements. The addition of the red-emitting component is useful to improve the color rendering, but human eye sensitivity is low in the red spectral region. So, it is quite difficult to obtain a high luminous efficacy and high color rendering simultaneously. Also, when the concentration of cyan and red phosphor films increases, luminous efficacy of the composite phosphor decreases due to their low thermal conductivities. The luminous efficacies of five combinations are higher than $701 \mathrm{~m} / \mathrm{W}$, of which only two concentration combinations have $R_{\mathrm{f}}$ and $R_{\mathrm{g}}$ greater than 90 . When the concentration of the red phosphor film is 1:1:0.01, the color temperature is between 3500 and $5000 \mathrm{~K}$, which is often used and suitable for indoor lighting. Only the sample with the red concentration of 1:1:0.01 (the mass ratio of glue A: glue $\left.\mathrm{B}:\left((\mathrm{Sr}, \mathrm{Ca}) \mathrm{AlSiN}_{3}: \mathrm{Eu}\right)\right)$, cyan phosphor concentration of 1:1:0.07 (the mass ratio of glue $A$ : glue $\mathrm{B}:\left(\mathrm{BaSi}_{2} \mathrm{~N}_{2} \mathrm{O}_{2}: \mathrm{Eu}\right)$, and $\mathrm{Ce}^{3+}$ concentration in YAG of 0.1 at $\%$ has a relatively high luminous efficacy $(75 \mathrm{~lm} / \mathrm{W})$. So, this concentration combination was chosen for further testing.

Figure 4 shows the EL spectra of WLEDs using different structures of three-layered phosphors. The input power of the blue LED was $1.5 \mathrm{~W}$. It is known that the red phosphor film can absorb the emission light of cyan and yellow phosphors, and the yellow phosphor can absorb the emission of the cyan phosphor, which will decrease the luminous efficacy and affect the color rendition of WLEDs (Fig. 3(d)). In order to improve the color rendering of WLEDs effectively, the red and 
Table 1 Optical properties of the COB packaged WLEDs with different concentrations of red and cyan phosphor films under the excitation of $460 \mathrm{~nm}$ blue LEDs with an input power of $1.5 \mathrm{~W}$

\begin{tabular}{|c|c|c|c|c|c|c|}
\hline $\begin{array}{c}\text { Mass ratio of } \\
\text { glue A:glue B: } \\
\left((\mathrm{Sr}, \mathrm{Ca}) \mathrm{AlSiN}_{3}: \mathrm{Eu}\right)\end{array}$ & $\begin{array}{l}\text { Mass ratio of } \\
\text { glue A:glue B: } \\
\left(\mathrm{BaSi}_{2} \mathrm{~N}_{2} \mathrm{O}_{2}: \mathrm{Eu}\right)\end{array}$ & $\begin{array}{c}\text { Concentration of } \\
\mathrm{Ce}^{3+} \text { in YAG }\end{array}$ & $\begin{array}{c}\text { Luminous } \\
\text { efficacy }(\operatorname{lm} / \mathrm{W})\end{array}$ & $\begin{array}{l}\text { Color coordinates } \\
\qquad(x, y)\end{array}$ & $\mathrm{CCT}(\mathrm{K})$ & $\left(R_{\mathrm{f}}, R_{\mathrm{g}}\right)$ \\
\hline $1: 1: 0.01$ & $1: 1: 0.05$ & 0.05 at $\%$ & 72 & $(0.37,0.40)$ & 4380 & $(92,95)$ \\
\hline $1: 1: 0.01$ & $1: 1: 0.05$ & $0.1 \mathrm{at} \%$ & 77 & $(0.40,0.42)$ & 3866 & $(88,90)$ \\
\hline $1: 1: 0.01$ & $1: 1: 0.05$ & 0.15 at $\%$ & 79 & $(0.40,0.44)$ & 3825 & $(87,91)$ \\
\hline $1: 1: 0.01$ & $1: 1: 0.07$ & 0.05 at $\%$ & 68 & $(0.36,0.40)$ & 4721 & $(90,95)$ \\
\hline $1: 1: 0.01$ & $1: 1: 0.07$ & $0.1 \mathrm{at} \%$ & 75 & $(0.39,0.42)$ & 3852 & $(93,97)$ \\
\hline 1:1:0.01 & $1: 1: 0.07$ & 0.15 at $\%$ & 72 & $(0.40,0.42)$ & 3886 & $(87,91)$ \\
\hline $1: 1: 0.01$ & 1:1:0.09 & 0.05 at $\%$ & 62 & $(0.35,0.41)$ & 4898 & $(83,92)$ \\
\hline $1: 1: 0.01$ & 1:1:0.09 & $0.1 \mathrm{at} \%$ & 68 & $(0.38,0.42)$ & 4193 & $(90,100)$ \\
\hline $1: 1: 0.01$ & $1: 1: 0.09$ & 0.15 at $\%$ & 57 & $(0.33,0.35)$ & 5408 & $(94,104)$ \\
\hline $1: 1: 0.02$ & $1: 1: 0.05$ & 0.05 at $\%$ & 60 & $(0.40,0.36)$ & 3257 & $(90,110)$ \\
\hline $1: 1: 0.02$ & $1: 1: 0.05$ & $0.1 \mathrm{at} \%$ & 62 & $(0.43,0.40)$ & 3027 & $(92,105)$ \\
\hline $1: 1: 0.02$ & $1: 1: 0.05$ & 0.15 at $\%$ & 57 & $(0.43,0.38)$ & 2877 & $(88,110)$ \\
\hline 1:1:0.02 & $1: 1: 0.07$ & 0.05 at $\%$ & 53 & $(0.41,0.36)$ & 3181 & $(89,110)$ \\
\hline $1: 1: 0.02$ & $1: 1: 0.07$ & $0.1 \mathrm{at} \%$ & 58 & $(0.43,0.39)$ & 3014 & $(93,106)$ \\
\hline $1: 1: 0.02$ & $1: 1: 0.07$ & 0.15 at $\%$ & 57 & $(0.44,0.39)$ & 2877 & $(90,108)$ \\
\hline $1: 1: 0.02$ & $1: 1: 0.09$ & 0.05 at $\%$ & 47 & $(0.42,0.38)$ & 3127 & $(82,107)$ \\
\hline $1: 1: 0.02$ & 1:1:0.09 & $0.1 \mathrm{at} \%$ & 53 & $(0.43,0.38)$ & 3081 & $(88,106)$ \\
\hline 1:1:0.02 & 1:1:0.09 & 0.15 at $\%$ & 49 & $(0.26,0.50)$ & 3004 & $(88,113)$ \\
\hline $1: 1: 0.03$ & $1: 1: 0.05$ & 0.05 at $\%$ & 52 & $(0.44,0.37)$ & 2615 & $(87,114)$ \\
\hline $1: 1: 0.03$ & $1: 1: 0.05$ & $0.1 \mathrm{at} \%$ & 57 & $(0.45,0.37)$ & 2481 & $(88,111)$ \\
\hline $1: 1: 0.03$ & $1: 1: 0.05$ & $0.15 \mathrm{at} \%$ & 54 & $(0.46,0.39)$ & 2471 & $(86,110)$ \\
\hline $1: 1: 0.03$ & $1: 1: 0.07$ & 0.05 at $\%$ & 45 & $(0.27,0.50)$ & 2562 & $(84,116)$ \\
\hline $1: 1: 0.03$ & $1: 1: 0.07$ & $0.1 \mathrm{at} \%$ & 52 & $(0.45,0.37)$ & 2634 & $(86,116)$ \\
\hline $1: 1: 0.03$ & $1: 1: 0.07$ & $0.15 \mathrm{at} \%$ & 50 & $(0.46,0.38)$ & 2469 & $(86,113)$ \\
\hline 1:1:0.03 & 1:1:0.09 & 0.05 at $\%$ & 39 & $(0.43,0.35)$ & 2539 & $(78,117)$ \\
\hline $1: 1: 0.03$ & $1: 1: 0.09$ & $0.1 \mathrm{at} \%$ & 46 & $(0.44,0.36)$ & 2485 & $(82,118)$ \\
\hline $1: 1: 0.03$ & $1: 1: 0.09$ & 0.15 at $\%$ & 41 & $(0.45,0.36)$ & 2405 & $(84,117)$ \\
\hline
\end{tabular}
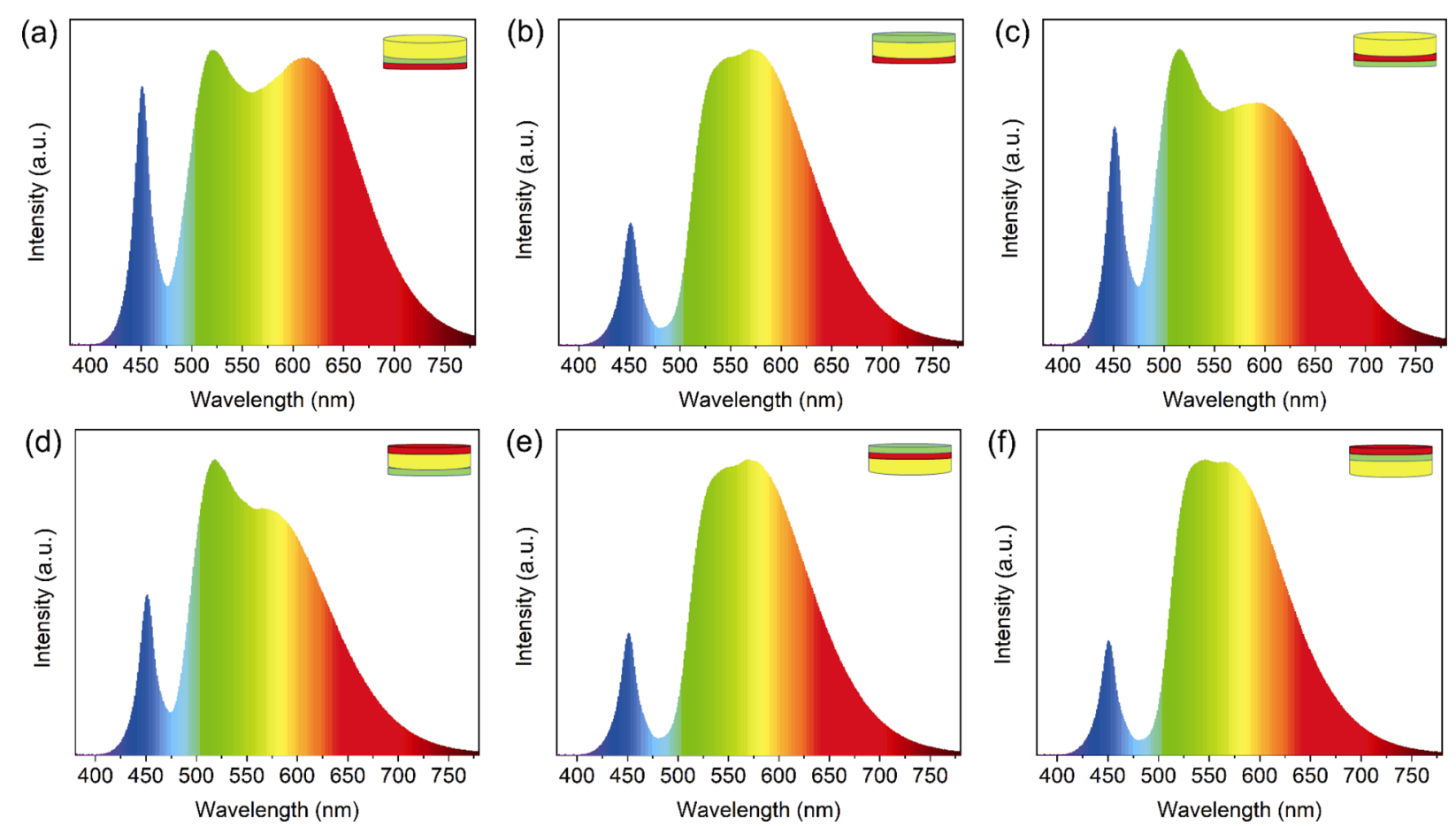

Fig. 4 EL spectra of WLEDs with different structures of three-layered phosphors: (a) $\mathrm{R}+\mathrm{C}+\mathrm{Y}$, (b) $\mathrm{R}+\mathrm{Y}+\mathrm{C}$, (c) $\mathrm{C}+\mathrm{R}+\mathrm{Y}$, (d) $\mathrm{C}+\mathrm{R}+\mathrm{Y}$, (e) $\mathrm{Y}+\mathrm{R}+\mathrm{C}$, and (f) $\mathrm{Y}+\mathrm{C}+\mathrm{R}$. 
cyan phosphor films, which are used to supplement the spectral component of YAG:Ce, should be placed close to the blue LED. As seen from the EL spectra of these composite phosphors with different structures in Fig. 4, the structures of $\mathrm{R}+\mathrm{C}+\mathrm{Y}$ (Fig. 4(a)) and $\mathrm{C}+\mathrm{R}+\mathrm{Y}$ (Fig. 4(c)) can fill the cyan and red light gaps. However, the WLED with the structure of $\mathrm{C}+\mathrm{R}+\mathrm{Y}$ has low color rendering. For the $\mathrm{R}+\mathrm{C}+\mathrm{Y}$ structure used for highpower lighting devices in reflection geometry, the YAG:Ce phosphor ceramic will contact with the heat sink substrate, enabling to dissipate the heat generated by the phosphor films and itself.

The Commission Internationale De L'Eclairage (CIE) chromaticity coordinates of WLEDs fabricated by using YAG:Ce ceramic and different structures of three-layered phosphors are shown in Fig. 5(a). In the composite phosphors, the thicknesses of YAG:Ce ceramic, $(\mathrm{Sr}, \mathrm{Ca}) \mathrm{AlSiN}_{3}: \mathrm{Eu}$ red film, and $\mathrm{BaSi}_{2} \mathrm{~N}_{2} \mathrm{O}_{2}: \mathrm{Eu}$ cyan film are 1.0, 0.4 , and $0.4 \mathrm{~mm}$, respectively. It can be seen that the color coordinates of all the WLEDs based on composite phosphor fall in the white light area. When the YAG:Ce phosphor ceramic or the cyan phosphor film is close to the blue LEDs, the obtained light is far from the black body radiation line and no longer white. In addition, the CCT value also changes when the structure of three-layered phosphors is different (Table 2). The obtained white light based on the structure of $\mathrm{R}+\mathrm{C}+\mathrm{Y}$ is closest to the blackbody line and can be used for neutral white light illumination. As shown in Fig. 5(b), although the surface temperature of the three-layered phosphors is higher than that of YAG:Ce, all of them are lower than $67{ }^{\circ} \mathrm{C}$ when they are excited by the blue LED, indicating that WLEDs using these composite phosphors can remain relatively high luminous efficacy while they work. As shown in Fig. 5(c), with the decrease of the YAG:Ce ceramic thickness in the $\mathrm{R}+\mathrm{C}+\mathrm{Y}$ structured composite phosphor, the color rendering and CCT of the WLED increase, and the luminous efficacy decreases. The emission light changes from warm light to cold light (Fig. 5(d)), approaching the blackbody radiation line, which is attributed to the different proportion of red, yellow, and cyan in the emitted light caused by the changed thickness of the ceramic. It is worth noting that the color coordinates of different structures can be closest to the blackbody line and can be used for neutral white light illumination by changing the thicknesses and concentrations of the cyan, yellow, and red phosphors. This result just provides a solution for phosphors with (a)

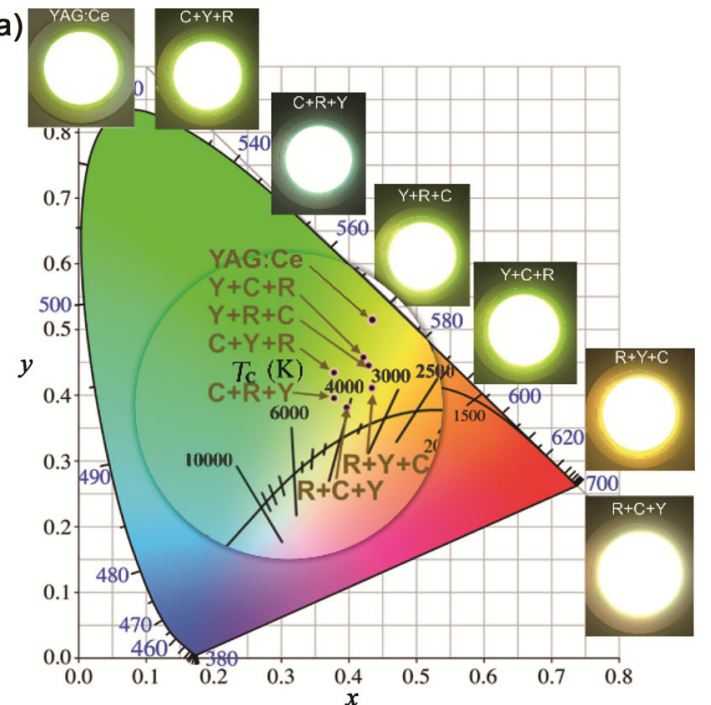

(b)
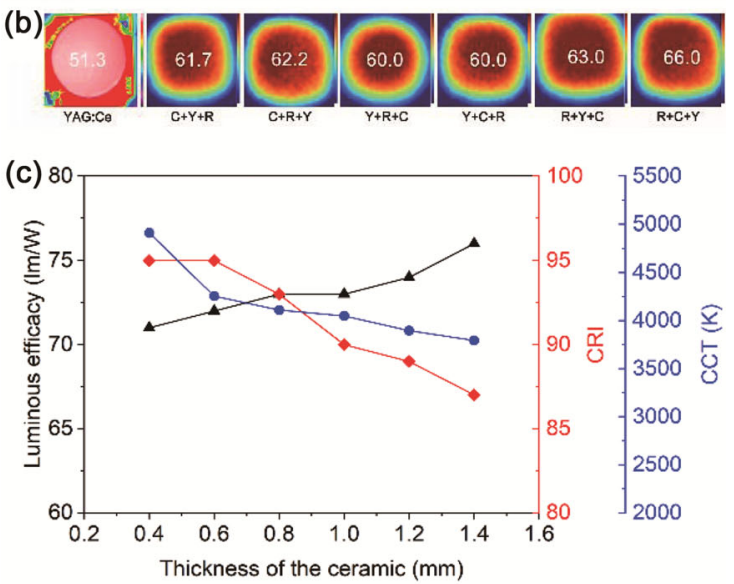

(d)

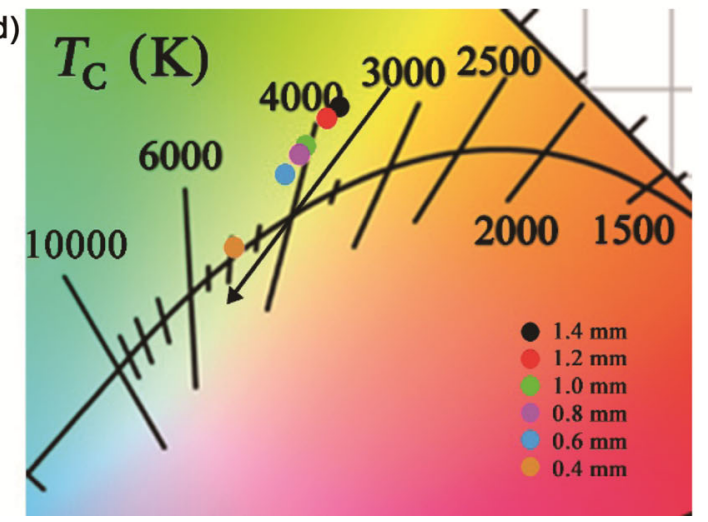

Fig. 5 (a) CIE chromaticity coordinates of WLEDs using YAG:Ce ceramic and different structures of the three-layered phosphors and $T_{\mathrm{C}}$ in (a) indicates the color temperature of the point; (b) the surface temperature of WLEDs in operation; (c) luminous efficacy, $R_{\mathrm{g}}, R_{\mathrm{f}}, \mathrm{CCT}$, and (d) CIE chromaticity coordinates of WLEDs based on the $\mathrm{R}+\mathrm{C}+\mathrm{Y}$ three-layered phosphor with different YAG:Ce ceramic thicknesses under the excitation of $460 \mathrm{~nm}$ blue LEDs with an input power of $1.5 \mathrm{~W}$.

specific thickness and concentration to change their color temperature and luminous efficacy by transforming 
Table 2 Optical properties of the COB packaged WLEDs with different structures of three-layered phosphors under the excitation of $460 \mathrm{~nm}$ blue LEDs with an input power of $1.5 \mathrm{~W}$

\begin{tabular}{ccccccc}
\hline $\begin{array}{c}\text { Structure of } \\
\text { three-layered } \\
\text { phosphor }\end{array}$ & $\begin{array}{c}\text { Luminous } \\
\text { flux }(\mathrm{lm})\end{array}$ & $\begin{array}{c}\text { Luminous } \\
\text { efficacy } \\
(\mathrm{lm} / \mathrm{W})\end{array}$ & $\begin{array}{c}\text { Color } \\
\text { coordinates } \\
(x, y)\end{array}$ & $\mathrm{CCT}(\mathrm{K})$ & $\left(R_{\mathrm{f}}, R_{\mathrm{g}}\right)$ \\
\hline $\mathrm{R}+\mathrm{C}+\mathrm{Y}$ & 106 & 75 & $(0.39,0.42)$ & 3852 & $(93,97)$ \\
$\mathrm{R}+\mathrm{Y}+\mathrm{C}$ & 128 & 90 & $(0.42,0.44)$ & 3573 & $(83,92)$ \\
$\mathrm{C}+\mathrm{R}+\mathrm{Y}$ & 112 & 77 & $(0.37,0.43)$ & 4489 & $(85,88)$ \\
$\mathrm{C}+\mathrm{Y}+\mathrm{R}$ & 133 & 89 & $(0.37,0.46)$ & 4691 & $(78,80)$ \\
$\mathrm{Y}+\mathrm{R}+\mathrm{C}$ & 146 & 100 & $(0.42,0.47)$ & 3809 & $(76,78)$ \\
$\mathrm{Y}+\mathrm{C}+\mathrm{R}$ & 151 & 106 & $(0.41,0.48)$ & 3972 & $(75,80)$ \\
\hline
\end{tabular}

the stack structure purposefully. By using this CIE chromaticity diagram, we can design the WLED devices with specific properties.

The luminous flux, luminous efficacy, and CCT of the WLEDs based on the $\mathrm{R}+\mathrm{C}+\mathrm{Y}$ three-layered phosphor as a function of incident pump power are demonstrated in Fig. 6. The luminous flux increases linearly with increasing the pump power, and it reaches a saturation threshold at $3.5 \mathrm{~W}$. The surface temperature of the three-layered phosphors can be up to $121{ }^{\circ} \mathrm{C}$ when the pump power is $4.44 \mathrm{~W}$ (Fig. 6(b)), so thermal quenching is the main reason for luminance saturation which leads to the decrease of luminous flux. Perhaps the thermal conductivity of the films is too low to dissipate the generated heat, so that the heat is accumulated and the temperature of the phosphors rises. The CCT value nearly does not change with the increase of the pump power, indicating that the white light is maintained. When LEDs are used for lighting, they will face a variety of extreme environmental conditions, such as long-term exposure to sun and rain, thunder and lighting, and large temperature changes, etc. Therefore, the variation EL spectra of $\mathrm{R}+\mathrm{C}+\mathrm{Y}$ three-layered samples before and after high-temperature and high-humidity $\left(85{ }^{\circ} \mathrm{C} / \mathrm{RH} 85 \%\right.$ ) test for 6 days were tested (Fig. 6(c)). After the test, the films still adhere to the ceramic and no change can be found in the composite phosphor. However, the EL intensity decreases after the test, which may be attributed to the hydrolysis of phosphors in the film.

In order to evaluate the potential of this composite phosphor for laser lighting, optical properties of the $\mathrm{R}+\mathrm{C}+\mathrm{Y}$ structured composite phosphor under the blue laser excitation were also measured. The blue laser

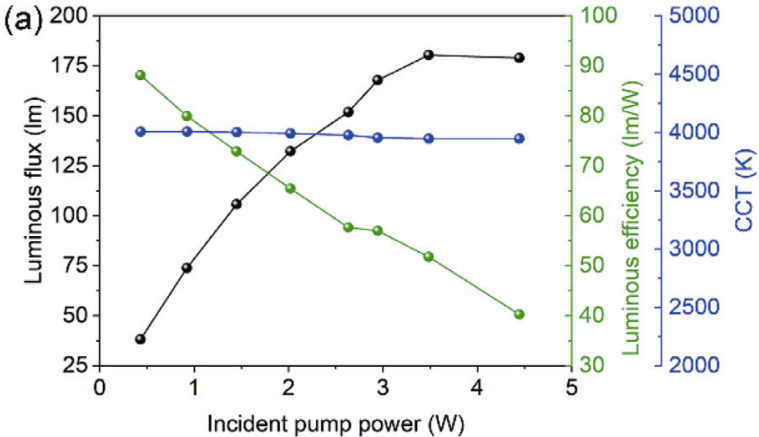

(b)

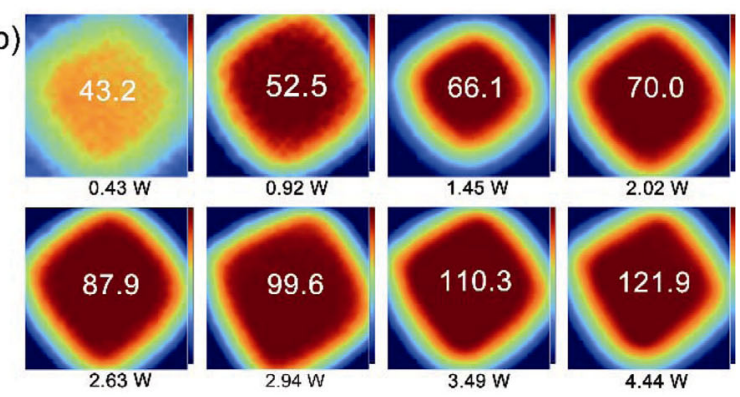

(c)

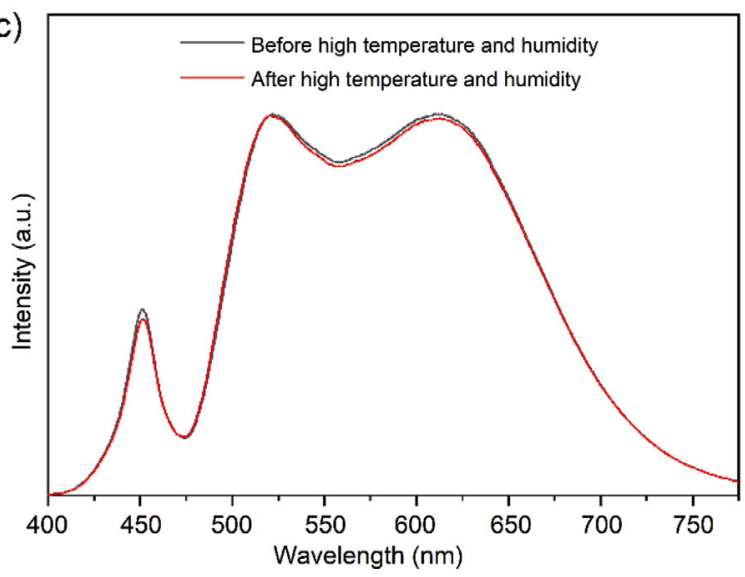

Fig. 6 (a) Luminous flux, luminous efficacy, and CCT of WLEDs based on the $\mathrm{R}+\mathrm{C}+\mathrm{Y}$ three-layered phosphor; (b) the surface temperature as a function of incident pump power; and (c) EL spectra of the $\mathrm{R}+\mathrm{C}+\mathrm{Y}$ three-layered phosphor before and after high-temperature and highhumidity test for 6 days.

power density was $0.92 \mathrm{~W} \cdot \mathrm{mm}^{-2}$. As seen from Fig. 7(a), the values of luminous efficacy, CRI, and CCT of the white light are $120 \mathrm{~lm} / \mathrm{W}, 90$, and $5988 \mathrm{~K}$, respectively. Big differences in the luminous efficacy and CCT of the " $\mathrm{R}+\mathrm{C}+\mathrm{Y}$ " three-layer phosphor have been found under LED excitation and under LD excitation. When the composite phosphor is excited by a high-power blue laser instead of a blue LED, the power density is higher and therefore more blue light is transmitted. The blue light is not converted and passes through the phosphor to participates in the final white light, so the color temperature and luminous efficacy of the obtained 

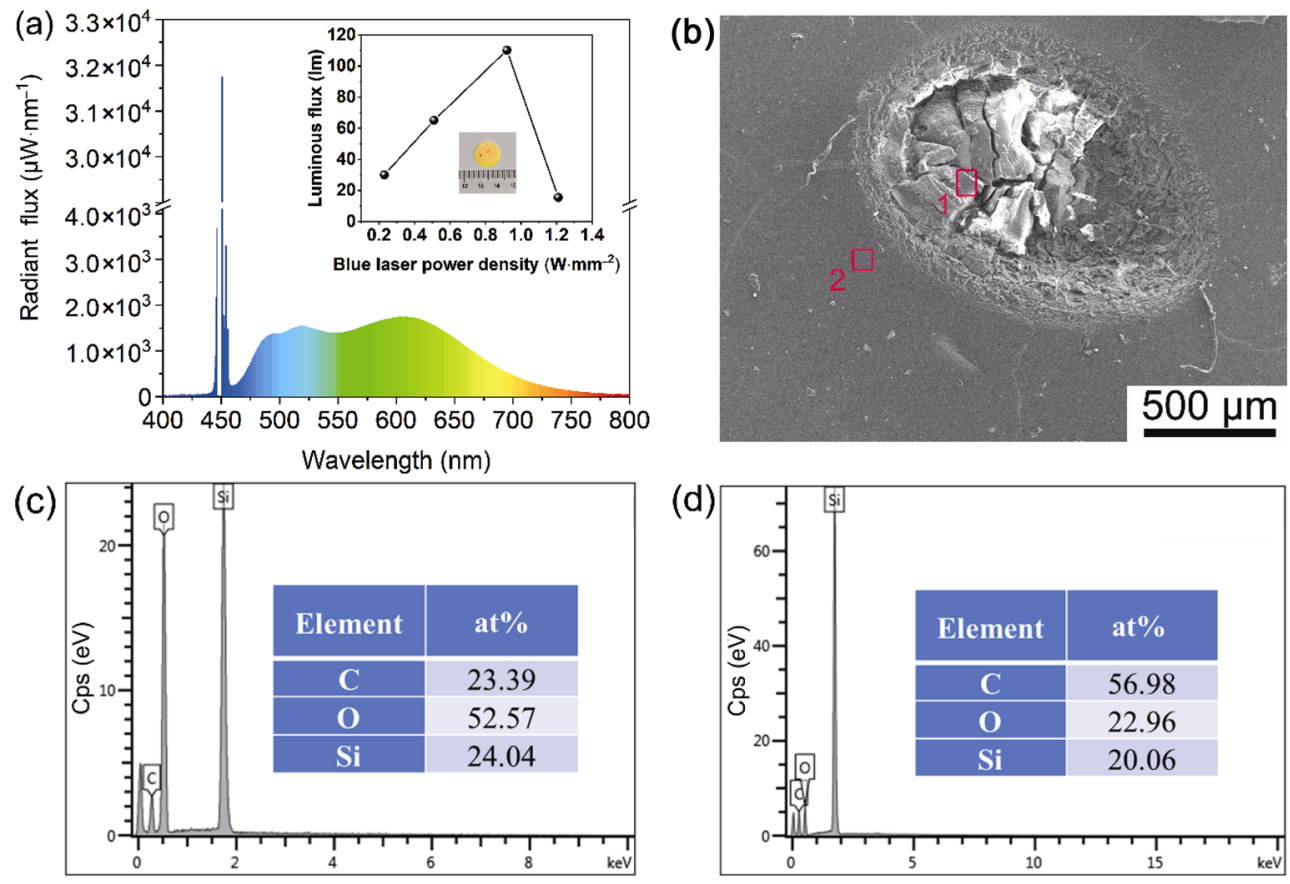

Fig. 7 (a) Emission spectrum of $\mathrm{R}+\mathrm{C}+\mathrm{Y}$ structured three-layered phosphor under the excitation of $450 \mathrm{~nm}$ blue laser with a laser power density of $0.92 \mathrm{~W} \cdot \mathrm{mm}^{-2}$. The inset shows the luminous flux as a function of blue laser power density and the photograph of the composite phosphor after the excitation of blue laser. (b) SEM morphology of the damaged area. EDS analyses of spectra: (c) 1 in (b) and (d) 2 in (b).

white light are higher than when the composite phosphor is excited by LEDs. The inset in Fig. 7(a) shows the luminous flux of the $\mathrm{R}+\mathrm{C}+\mathrm{Y}$ structured phosphor as a function of the blue laser power density. The luminous flux reaches its maximum at 0.92 $\mathrm{W} \cdot \mathrm{mm}^{-2}$, and decreases abruptly at $1.2 \mathrm{~W} \cdot \mathrm{mm}^{-2}$. The sharp decrease can be ascribed to the carbonization of the phosphor films when they are pumped by the blue laser. As shown in the inset of Fig. 7(a), two black spots on the composite phosphor where the blue laser excites can be observed. Obvious pits can be observed in the damaged area (Fig. 7(b)). According to the EDS results in Figs. 7(c) and 7(d), the elements in the pits are C, O, and $\mathrm{Si}$, and the undamaged area outside the pits contains more C. Because $\mathrm{C}$ in the damaged area is released into the air in the form of $\mathrm{CO}_{2}$ after combining with $\mathrm{O}$ in the air under the excitation of high-power density blue laser. Therefore, the phosphor film containing organic binders is not suitable for laser lighting, and all inorganic color converters with high thermal stability or thermal conductivity need to be developed.

\section{Conclusions}

In this work, to realize high color rendering lighting, we proposed coating both the cyan-emitting $\mathrm{BaSi}_{2} \mathrm{~N}_{2} \mathrm{O}_{2}$ : $\mathrm{Eu}$ and red-emitting $(\mathrm{Sr}, \mathrm{Ca}) \mathrm{AlSiN}_{3}: \mathrm{Eu}$ phosphor films on the yellow-emitting YAG:Ce phosphor ceramic. The optimal composition of the cyan film, red film, and yellow ceramic was 1:1:0.07 (the mass ratio of glue A:glue B:(( $\left.\left.\mathrm{BaSi}_{2} \mathrm{~N}_{2} \mathrm{O}_{2}: \mathrm{Eu}\right)\right), 1: 1: 0.01$ (the mass ratio of glue A:glue $\left.\mathrm{B}:\left((\mathrm{Sr}, \mathrm{Ca}) \mathrm{AlSiN}_{3}: \mathrm{Eu}\right)\right)$, and $\mathrm{Ce}^{3+}$ concentration in YAG of 0.1 at $\%$, respectively. Also, the structure or the stacking sequence of the three-layered phosphors had a great influence on the luminous efficacy and color rendering properties of WLEDs. By combining with a COB blue LED, the sample with a structure of $\mathrm{R}+\mathrm{C}+\mathrm{Y}$ three-layered phosphors generated neutral white light with the luminous efficacy of $75 \mathrm{~lm} / \mathrm{W}, R_{\mathrm{f}}$ of $93, R_{\mathrm{g}}$ of 97 , and CCT of $3852 \mathrm{~K}$. The luminous flux reached a saturation threshold when the incident pump power was $3.5 \mathrm{~W}$, which can be attributed to the thermal quenching of phosphor films. Under the blue laser excitation, the values of luminous efficacy, CRI, and CCT of the white light are $120 \mathrm{~lm} / \mathrm{W}, 90$, and $5988 \mathrm{~K}$, respectively. However, the luminance saturation of the same sample was as low as $0.92 \mathrm{~W} \cdot \mathrm{mm}^{-2}$. In our future work, to increase the threshold of luminance saturation, full-inorganic muti-layered phosphors with higher thermal conductivities will be prepared to keep the temperature of the phosphor as low as possible. 


\section{Acknowledgements}

This work was supported by the National Key R\&D Program of China (Grant No. 2017YFB0310500), the National Natural Science Foundation of China (Grant No. 61775226), the Strategic Priority Research Program of Chinese Academy of Sciences (Grant No. XDA22010301), and the key research project of the frontier science of the Chinese Academy of Sciences (No. QYZDB-SSW-JSC022).

\section{References}

[1] Haitz R, Tsao JY. Solid-state lighting: 'The case' 10 years after and future prospects. Phys Status Solidi (a) 2011, 208: 17-29.

[2] Wierer JJ, Tsao JY, Sizov DS. Comparison between blue lasers and light-emitting diodes for future solid-state lighting. Laser Photonics Rev 2013, 7: 963-993.

[3] Tsao JY, Crawford MH, Coltrin ME, et al. Toward smart and ultra-efficient solid-state lighting. Adv Opt Mater 2014, 2: 809-836.

[4] $\mathrm{Xu} \mathrm{J}$, Thorseth $\mathrm{A}, \mathrm{Xu} \mathrm{C}$, et al. Investigation of laserinduced luminescence saturation in a single-crystal YAG:Ce phosphor: Towards unique architecture, high saturation threshold, and high-brightness laser-driven white lighting. J Lumin 2019, 212: 279-285.

[5] Song YH, Kwon SB, Jung MK, et al. Fabrication design for a high-quality laser diode-based ceramic converter for a laser headlamp application. Ceram Int 2018, 44: 11821186.

[6] Arjoca S, Víllora EG, Inomata D, et al. Temperature dependence of Ce:YAG single-crystal phosphors for high-brightness white LEDs/LDs. Mater Res Express 2015, 2: 055503 .

[7] Li SX, Wang L, Hirosaki N, et al. Color conversion materials for high-brightness laser-driven solid-state lighting. Laser Photonics Rev 2018, 12: 1800173.

[8] Lin H, Hu T, Cheng Y, et al. Glass ceramic phosphors: Towards long-lifetime high-power white light-emittingdiode applications-A review. Laser Photonics Rev 2018, 12: 1700344.

[9] Nishiura S, Tanabe S, Fujioka K, et al. Properties of transparent Ce:YAG ceramic phosphors for white LED. Opt Mater 2011, 33: 688-691.

[10] Wei N, Lu TC, Li F, et al. Transparent Ce: $\mathrm{Y}_{3} \mathrm{Al}_{5} \mathrm{O}_{12}$ ceramic phosphors for white light-emitting diodes. Appl Phys Lett 2012, 101: 061902.

[11] Ji C, Ji LY, Lian LC, et al. Low-temperature solution synthesis and characterization of Ce-doped YAG nanoparticles. J Rare Earth 2015, 33: 591-598.

[12] Liu GH, Zhou ZZ, Shi Y, et al. Ce:YAG transparent ceramics for applications of high power LEDs: Thickness effects and high temperature performance. Mater Lett 2015, 139: $480-482$.
[13] Zheng P, Li SX, Wei R, et al. Unique design strategy for laser-driven color converters enabling superhighluminance and high-directionality white light. Laser Photonics Rev 2019, 13: 1900147.

[14] Hua H, Feng SW, Ouyang ZY, et al. YAGG:Ce transparent ceramics with high luminous efficiency for solid-state lighting application. $J A d v$ Ceram 2019, 8: 389-398.

[15] Feng SW, Qin HM, Wu GQ, et al. Spectrum regulation of YAG:Ce transparent ceramics with $\mathrm{Pr}, \mathrm{Cr}$ doping for white light emitting diodes application. J Eur Ceram Soc 2017, 37: 3403-3409.

[16] Shao XC, Zhou SM, Tang YR, et al. Luminescence characteristics of Ce:YAG ceramic phosphors with $\mathrm{Gd}^{3+}$ doping for white light-emitting diodes. J Inorg Mater 2018, 33: 1119-1123. (in Chinese)

[17] Nishiura S, Tanabe S, Fujioka K, et al. Preparation of transparent $\mathrm{Ce}^{3+}$ :GdYAG ceramics phosphors for white LED. IOP Conf Ser: Mater Sci Eng 2011, 18: 102005.

[18] Liu X, Zhou HY, Hu ZW, et al. Transparent Ce:GdYAG ceramic color converters for high-brightness white LEDs and LDs. Opt Mater 2019, 88: 97-102.

[19] Ling JR, Zhou YF, Xu WT, et al. Red-emitting YAG:Ce, Mn transparent ceramics for warm WLEDs application. $J$ Adv Ceram 2020, 9: 45-54.

[20] Pricha I, Rossner W, Moos R. Layered ceramic phosphors based on $\mathrm{CaAlSiN}_{3}: \mathrm{Eu}$ and YAG:Ce for white light-emitting diodes. J Am Ceram Soc 2016, 99: 211-217.

[21] Legentil P, Leroux F, Therias S, et al. Sulforhodamine B-LDH composite as a rare-earth-free red-emitting phosphor for LED lighting. J Mater Chem C 2020, 8: 11906-11915.

[22] Nyalosaso JL, Boonsin R, Vialat P, et al. Towards rare-earth-free white light-emitting diode devices based on the combination of dicyanomethylene and pyranine as organic dyes supported on zinc single-layered hydroxide. Beilstein J Nanotechnol 2019, 10: 760-770.

[23] Li SX, Zhu QQ, Wang L, et al. $\mathrm{CaAlSiN}_{3}: \mathrm{Eu}^{2+}$ translucent ceramic: A promising robust and efficient red color converter for solid state laser displays and lighting. J Mater Chem C 2016, 4: 8197-8205.

[24] Wang L, Xie RJ, Li YQ, et al. $\mathrm{Ca}_{1-x} \mathrm{Li}_{x} \mathrm{Al}_{1-x} \mathrm{Si}_{1+x} \mathrm{~N}_{3}: \mathrm{Eu}^{2+}$ solid solutions as broadband, color-tunable and thermally robust red phosphors for superior color rendition white light-emitting diodes. Light: Sci Appl 2016, 5: e16155.

[25] Wang L, Xie RJ, Suehiro T, et al. Down-conversion nitride materials for solid state lighting: Recent advances and perspectives. Chem Rev 2018, 118: 1951-2009.

[26] Oh JH, Yang SJ, Do YR. Healthy, natural, efficient and tunable lighting: Four-package white LEDs for optimizing the circadian effect, color quality and vision performance. Light: Sci Appl 2014, 3: e141.

[27] Yan CP, Zhuang WD, Liu RH, et al. Dehydrogenationdriven to synthesize high-performance $\mathrm{Lu}_{2} \mathrm{Si}_{4} \mathrm{~N}_{6} \mathrm{C}: \mathrm{Ce}^{3+}$-a broad green-emitting phosphor for full-spectrum lighting. $J$ Alloys Compd 2019, 783: 855-862. 
[28] Fang MH, Ni CC, Zhang XJ, et al. Enhance color rendering index via full spectrum employing the important key of cyan phosphor. ACS Appl Mater Interfaces 2016, 8: 30677-30682.

[29] Zhao M, Xia Z, Huang X, et al. Li substituent tuning of LED phosphors with enhanced efficiency, tunable photoluminescence, and improved thermal stability. Sci $A d v$ 2019, 5: eaav0363.

[30] Zhao M, Liao H, Molokeev MS, et al. Emerging ultra-narrow-band cyan-emitting phosphor for white LEDs with enhanced color rendition. Light Sci Appl 2019, 8: 38.

[31] Zhang YP, Luo L, Chen GT, et al. Green and red phosphor for LED backlight in wide color gamut LCD. J Rare Earth 2020, 38: $1-12$.

[32] Liang $\mathrm{MZ}, \mathrm{Xu} \mathrm{JF}$, Qiang $\mathrm{YC}$, et al. $\mathrm{Ce}^{3+}$ doped $\mathrm{BaLu}_{2} \mathrm{Al}_{2} \mathrm{Ga}_{2} \mathrm{SiO}_{12}$ - $\mathrm{A}$ novel blue-light excitable cyanemitting phosphor with ultra-high quantum efficiency and excellent stability for full-spectrum white LEDs. $J$ Rare Earth 2020, https://doi.org/10.1016/j.jre.2020.09.015.

[33] Kimura N, Sakuma K, Hirafune S, et al. Extrahigh color rendering white light-emitting diode lamps using oxynitride and nitride phosphors excited by blue lightemitting diode. Appl Phys Lett 2007, 90: 051109.

[34] Li YQ, Delsing ACA, de With G, et al. Luminescence properties of $\mathrm{Eu}^{2+}$-activated alkaline-earth silicon-oxynitride $\mathrm{MSi}_{2} \mathrm{O}_{2-\delta} \mathrm{N}_{2+2 / 3 \delta}(\mathrm{M}=\mathrm{Ca}, \mathrm{Sr}, \mathrm{Ba})$ : A promising class of novel LED conversion phosphors. Chem Mater 2005, 17: 3242-3248.

[35] Zhang $\mathrm{YL}, \mathrm{Hu} \mathrm{S}$, Wang $\mathrm{ZJ}$, et al. Pore-existing $\mathrm{Lu}_{3} \mathrm{Al}_{5} \mathrm{O}_{12}$ :Ce ceramic phosphor: An efficient green color converter for laser light source. J Lumin 2018, 197: 331-334.

[36] Fujita S, Sakamoto A, Tanabe S. Luminescence characteristics of YAG glass-ceramic phosphor for white LED. IEEE J Sel Top Quantum Electron 2008, 14: 13871391.

[37] Li Y, Hu LL, Yang BB, et al. Thermal stability and reliability studies of $(\mathrm{Sr}, \mathrm{Ca}) \mathrm{AlSiN}_{3}: \mathrm{Eu}^{2+}$ phosphors for LED application. J Mater Sci: Mater Electron 2017, 28:
19155-19163.

[38] Liu XL, Song Z, Wang SX, et al. The red persistent luminescence of $(\mathrm{Sr}, \mathrm{Ca}) \mathrm{AlSiN}_{3}: \mathrm{Eu}^{2+}$ and mechanism different to $\mathrm{SrAl}_{2} \mathrm{O}_{4}: \mathrm{Eu}^{2+}, \mathrm{Dy}^{3+}$. J Lumin 2019, 208: 313321.

[39] Wang QY, Dong Y, Shao QY, et al. Low-pressure preparation of Eu-Doped $(\mathrm{Sr} / \mathrm{Ca}) \mathrm{AlSiN}_{3}$ with $\mathrm{Li}_{3} \mathrm{~N}$ flux and its thermal quenching properties. Optoelectron $A d v$ Mater-Rapid Commun 2018, 12: 95-99.

[40] Yao FF, Wang L, Lv Y, et al. Composition-dependent thermal degradation of red-emitting $\left(\mathrm{Ca}_{1-x} \mathrm{Sr}_{x}\right) \mathrm{AlSiN}_{3}: \mathrm{Eu}^{2+}$ phosphors for high color rendering white LEDs. $J$ Mater Chem C 2018, 6: 890-898.

[41] Bachmann V, Ronda C, Meijerink A. Temperature quenching of yellow $\mathrm{Ce}^{3+}$ luminescence in YAG:Ce. Chem Mater 2009, 21: 2077-2084.

[42] Wang YH, Ding JY, Wang YC. et al. Structural design of new $\mathrm{Ce}^{3+} / \mathrm{Eu}^{2+}$-doped or co-doped phosphors with excellent thermal stabilities for WLEDs. $J$ Mater Chem $C$ 2019, 7: 1792-1820.

[43] Que MD, Ci ZP, Wang YH, et al. Crystal structure and luminescence properties of a cyan emitting $\mathrm{Ca}_{10}\left(\mathrm{SiO}_{4}\right)_{3}\left(\mathrm{SO}_{4}\right)_{3} \mathrm{~F}_{2}: \mathrm{Eu}^{2+}$ phosphor. CrystEngComm 2013, 15: 6389-6394.

Open Access This article is licensed under a Creative Commons Attribution 4.0 International License, which permits use, sharing, adaptation, distribution and reproduction in any medium or format, as long as you give appropriate credit to the original author(s) and the source, provide a link to the Creative Commons licence, and indicate if changes were made.

The images or other third party material in this article are included in the article's Creative Commons licence, unless indicated otherwise in a credit line to the material. If material is not included in the article's Creative Commons licence and your intended use is not permitted by statutory regulation or exceeds the permitted use, you will need to obtain permission directly from the copyright holder.

To view a copy of this licence, visit http://creativecommons. org/licenses/by/4.0/. 